\title{
Scientific Program of the 9th Canadian Congress of Neurological Sciences 9e Congrès Canadien des Sciences Neurologiques
}

\author{
Saskatoon, June 19th - 22nd, 1974
}

PARTICIPATING SOCIETIES:

Canadian Neurological Society

Canadian Neurosurgical Society

Canadian Society of Electroencephalographers, Electromyographers and Clinical Neurophysiologists

Associated Society:

Canadian Association of Neurological and Neurosurgical Nurses

Officers of the Congress:

President - Dr. J. G. Stratford

Director of Congress:

Dr. K. W. E. Paine

Program Committee:

Dr. C. Tator (Chairman)

\section{OFFICERS OF THE SOCIETIES}

Canadian Neurological Society:

President - Dr. E. M. Ashenhurst

Past-President - Dr. André Barbeau

Vice-President - Dr. Arthur Hudson

Secretary - Dr. Frederick Andermann

Canadian Neurosurgical Society:

President - Dr. J. G. Statford

Past-President - Dr. K. W. E. Paine

Vice-President - Dr. E. B. Hendrick

Secretary - Dr. H. W. K. Barr

Canadian Society of Electroencephalographers, Electromyographers and Clinical Neurophysiologists:

President - Dr. Morton Low

Past-President - Dr. Frederick Andermann

Treasurer - Dr. Douglas McGreal

Secretary - Dr. Katherine Metrakos

Canadian Association of Neurological and Neurosurgical Nurses:

President - Mrs. Mimi Reid

Past-President - Miss Suzanne Good

President Elect - Miss E. Jane Clattenburg

Secretary - Mrs. Marion J. McKenzie

Congress Headquarters:

Bessborough Hotel, Saskatoon, Saskatchewan

Distinguished Guest of the Congress

Dr. Kris Kristiansen

Oslo, Norway

\section{SCIENTIFIC PROGRAM}

Thursday, June 20, 1974 - Morning Session

Opening of Congress and Presidential Address - J. G. Stratford, President "Neurosurgical Manpower in Canada"

Scientific Session -

Symposium I "Advances in the Diagnosis and Treatment of Occlusive Cerebrovascular Disease"'

Chairmen: Dr. H. J. M. Barnett, Dr. H. W. Barr

Introduction - H. J. M. Barnett

Regional Cerebral Blood Flow Studies in Man: Technique and Applications

D. Simard, J. C. Pechadre, Quebec City

Cerebrovascular Dementia:

A Clinical and Cerebral Blood Flow Study

V. C. Hachinski, Toronto; L. D. Iliff, E. Zilkha, J. W. D. Bull, G. H. DuBoulay, V. L. McAllister, J. Marshall, R. W. Ross Russell, L. Symon, National Hospital, Queen Square, London, England.

Twenty-four patients of comparable age, blood pressure and degree of dementia were classified by an 'Ischemic Score based on clinical features into 'ischemic' and 'primary degenerative' dementia. Regional cerebral blood flow was measured by the intracarotid 133 Xe method. Both groups showed a decreased proportion of rapidly clearing brain tissue (largely gray matter). CBF per $100 \mathrm{~g}$ brain per minute was normal in the primary degenerative group but low in the ischemic group. This suggests that blood flow is adequate for the metabolic needs of the brain in primary degenerative dementia but inadequate in ischemic dementia. There was no correlation between the degree of dementia and CBF in the primary degenerative group but an inverse relationship existed in the ischemic group. Reactivity of blood vessels to reduction of $\mathrm{pCO}_{2}$ was normal in both groups. Selected cases of ischemic dementia may benefit from vasoactive drugs, anticoagulants or surgery.

The Advantages of the EMI Scan in the Diagnosis of the "Stroke" Patient

W. Feindel, R. Ethier, Montreal

Computerized axial transverse $\mathrm{x}$-ray tomography developed by Hounsfield and applied clinically by Ambrose offers a safe, rapid and simple method of neurological diagnosis. It provides 
an anatomical image of the intracranial contents seen in horizontal cross-section.

Normal tissue, grey and white matter, ventricles, subarachnoid spaces and cisterns as well as the calcified pineal gland and choroid plexuses can be seen because of their differing $x$-ray densities. Many intracranial abnormalities can be identified because of tissue densities above and below normal ranges.

Among these perhaps the most striking are intracranial hematomas of various types and locations. For the first time it is also possible to make a differential diagnosis between hematoma and infarct, a crucial advantage in the early management of the "stroke" patient. From the first 400 patients examined at the Montreal Neurological Institute those with vascular lesions of the brain were selected for review. Our results will also be compared with the series selected for review. Our results will also be compared with the series of Ambrose and Paxton resulting from the analysis of 650 patients scanned at the Atkinson Morley's Hospital with the prototype instrument.

The following main advantages were noted:

1) Intracranial hematomas are clearly displayed because of their high x-ray density. They can be identified as to site, size, configuration, relation to ventricles, and whether deep, superficial or intraventricular. Thus, the decision for or against conservative management can be based on more rational grounds.

2) Ischemic infarcts are seen as areas of low x-ray density and are thus clearly distinguishable from hematomas.

3) Since the EMI-scan is readily repeatable, the evolution of the acute cerebrovascular lesion can be followed at selected intervals with little risk or discomfort to the patient.

4) Angiomas can be identified by intravascular concentrations of Hypaque given intravenously.

5) Non-vascular lesions simulating clinically the picture of a stroke can be usually differentiated.

These points will be illustrated by representative examples.

\section{Transient Global and Permanent Amnesia of Cerebral Vascular Origin}

\section{J. D. Spence, H. J. M. Barnett, J. M. Allcock, London}

Cerebral arteriosclerosis is overemphasized as an explanation for dementia and defective memory in older patients. Without serious hypertension or obvious evidence of cerebral infarction, other causes for dementia are to be sought.

Permanent amnestic syndromes as a result of cerebrovascular diseases are rare; only eight cases are recorded. The authors studied seven patients with persistent loss of recent memory that was abrupt in onset and of vascular origin. Although other intellectual functions were spared, defective memory deprived the patients of employability. Visual disturbance coincided with the memory disturbance in all patients. One had had a previous contralateral temporal lobectomy, and three had previous contralateral visual disturbance. Sensory disturbance was persistent and bilateral in one patient; transient sensory symptoms occurred in one and transient motor symptoms in two other patients, clearing in hours.

Five cases were confirmed by angiography, one by radioisotope evidence and one by unequivocal clinical evidence, to have definite impairment in posterior cerebral artery territory. Involvement was bilateral in five and left-sided in the unilateral cases. Two additional patients were reported in whom a transient amnestic event was part of the evaluation of frank ischemia of vertebrobasilar territory.
The chronology of the cases suggested that the vascular territory which, when rendered ischemic, gives rise to the amnestic syndrome, is the territory of the remaining normal posterior cerebral artery in a patient with previous contralateral damage. Transient ischemia gives rise to transient global amnesia; infarction leaves a permanent amnestic syndrome.

\section{Dexamethasone Therapy in Acute Cerebral Infarction}

John W. Norris and F. Demanuele, Toronto

Patients with acute cerebral infarction occurring within 24 hours prior to hospital admission were randomly allocated to a placebo or active drug (dexamethasone) group. Diagnosis was made on a combination of clinical, radiological, brain scan, lumbar puncture and angiographic criteria. Cases revealing evidence of cerebral haemorrhage (during treatment or at autopsy) were withdrawn. Also, transient ischemic attack cases were excluded. If life threatening cerebral edema occurred, the pharmaceutical code was broken and dexamethasone substituted if necessary. Patients were assessed weekly for scores of stroke 'severity' and the results analysed statistically.

Forty-one patients completed the trial, and there was no statistical difference in stroke morbidity between the two groups. More patients died in the dexamethasone group and two developed severe gastrointestinal haemorrhage. Severe hyperglycemia occurred in several mild diabetics and thereafter all diabetics were excluded from the trial. Evidence therefore that dexamethasone confers any benefit when given routinely in acute cerebral infarction was lacking. More significantly, it did not appear that this drug prevented the evolution of progressive and sometimes fatal cerebral edema, even when administered in the earliest stages.

\section{Extracranial to Intracranial Microvascular Anastomosis A report of $\mathbf{5 0}$ cases}

\section{S. J. Peerless, Vancouver - N. Chater, Los Angeles}

An attempt to improve the perfusion of the brain by microsurgical anastomosis of the superficial temporal artery to branches of the middle cerebral artery has been carried out in $\mathbf{5 0}$ patients with severe occlusive cerebral vascular disease. All patients had clinical and angiographic evidence of impaired cerebral perfusion but none had a major fixed neurological deficit. Most patients suffered from repeated attacks of transient ischemia, but two patients with severe cerebral hypofusion demonstrated widespread neuronal dysfunction without neuronal death. Clinical and angiographic follow-up ranges from 4 years 10 months to 6 months.

From this study some observations regarding patient selection; refinements in surgical technique, intraoperative electromagnetic flow studies, results, and a simple method of testing postoperative patency will be made.

\section{Stump Pressure during Carotid Endarterectomy \\ H. Schutz, Toronto}

It is estimated that $10 \%$ of patients subjected to carotid endarterectomy suffer additional ischemic or embolic consequences due to temporary clamping of the common, external and internal carotid arteries (ICA). A number of intraoperative techniques have been devised which attempt to recognize those patients whose collateral circulation is inadequate to maintain cerebral function. They include measurement of $\mathrm{pO}_{2}$ and lactate concentrations in the internal jugular vein, E.E.G. monitoring, measurement of total or regional cerebral blood flow, visual estimation of ICA back flow and ICA stump pressure. Some of 
these measures are inaccurate and others are too cumbersome. We have found the stump pressure to be a simple, safe and valuable guide in the assessment of the patient's collateral circulation during 14 endarterectomies.

In 20 animals we have described a direct relationship between cerebral venous outflow pressure (analogous to stump pressure) and cerebral blood flow. This information suggests that stump pressure is a valid indicator of collateral circulation. In other experiments we have shown that cerebral hypoxia (fall in energy charge) results if the cerebral perfusion pressure drops below $30-40 \mathrm{~mm} \mathrm{Hg}$. Accordingly we have used a temporary by-pass shunt whenever the stump pressure fell below $40 \mathrm{~mm}$ $\mathrm{Hg}$ at a $\mathrm{pCO}_{2}$ of $40 \mathrm{~mm} \mathrm{Hg}$. These findings are in agreement with Moore and Hall who found that stump pressures below $30-40 \mathrm{~mm} \mathrm{Hg}$ were accompanied by additional ischemic episodes. Since the stump pressure was below $40 \mathrm{~mm} \mathrm{Hg}$ in only one patient, we feel that most ischemic episodes are due to emboli arising from the area of the endarterectomy.

This paper will review the cerebral hemodynamic changes that occur during carotid clamp-off and discuss the methods designed to recognize intraoperative cerebral hypoxia.

\section{CLOSING REMARKS - H. W. Barr}

\section{Malignant Hyperthermia in the Maritimes}

\section{Silver, T. J. Murray and J. A. R. Tibbles, Halifax}

The syndrome of Malignant Hyperthermia (MHT) may present to the neurologists as an obscure cause of coma following anaesthesia associated with either rigidity or flaccidity, as a complication of drug ingestion, particularly tricyclic antidepressants or as a potential anaesthetic hazard linked to an expanding number of myopathies and musculoskeletal diseases.

Four cases of MHT have been encountered in Nova Scotia. In an attempt to discover relatives at risk, creatine phosphokinase (CPK) assays have been performed. The mean value and standard deviations for CPK in our centre by our laboratory had previously been determined. In one family $150 \mathrm{CPK}$ assays have been carried out on relatives of the index case. Twentyfive members of this family had CPK values more than 2 standard deviations above the mean, yet only two fatalities complicating anaesthesia have been recorded in this kindred. Among those with abnormal CPK values, 21 anaesthetics have been administered without complication, suggesting that the risk is low in this particluar family. Our genetic data indicate a dominant mode of inheritance.

No evidence of myopathy was apparent on clinical examination of any member of the 4 families examined, but a limited number of muscle biopsies indicates an incidence of abnormalities that has caused us to recommend this test to high risk members.

An aggressive program has been adopted of counselling the families, family practitioners and local hospitals to lessen what is usually a major hazard to affected families.

\section{Binding of Tritiated-Ouabain as a Measurement of Sodium- Potassium Transport in Peripheral Nerve and Muscle \\ Garth M. Bray, Montreal}

Resting membrane potentials, as well as the important properties of excitability and impulse transmission which characterize nerve and muscle, are dependent on concentration gradients of $\mathrm{Na}^{+}$and $\mathrm{K}+$. Because these ionic gradients are due to a plasma membrane ATPase which can be identified biochemically by its sensitivity to cardiac glycosides such as ouabain, the present experiments were designed to assess the usefulness of measuring the amount of isotope-labelled ouabain bound by peripheral nerve and skeletal muscle fibers. Such a technique, if feasible, would provide a simple method for measuring "sodium-pump" sites in these tissues.

Segments of peripheral nerve and suspensions of skeletal muscle fibers were prepared from normal mice, incubated with tritium-labelled ouabain, rinsed to remove unbound ouabain, solubilized and counted by liquid scintillation spectrometry.

Both nerve and muscle fiber segments bound significant amounts of tritiated ouabain. Furthermore, more than $50 \%$ of the binding was inhibited by $\mathrm{KCL}$, indicating that most of the bound ouabain was specifically attached to sodium-pump sites. Because of this specificity, this ouabain-binding technique is being used to study $\mathrm{Na}^{+}-\mathrm{K}^{+}$transport function in disorders of peripheral nerve and muscle.

\section{An Electrophysiological and Pathological Study of Porphyric Neuropathy}

W. F. E. Brown, T. E. Feasby, J. Gilbert, M. W. Jones, London, Ontario

Reported studies of the acute intermittent porphyric neuropathy conflict, some studies pointing to segmental demyelination and others to axonal degeneration as the main histopathological abnormality of the peripheral nerves. The present study of a 30-year-old man with acute intermittent porphyria has shown extensive denervation, severe motor unit loss (based on new methods for estimating motor unit numbers), normal conduction velocities, tendon and $H$ reflex latencies, near normal sensory action potentials, and a substantial reduction in the size but little temporal dispersion of the compound nerve action potentials of the sural nerve in vitro. Repeated motor unit estimates showed a progressive loss of motor units which paralleled the clinical course.

An electron microscopic study showed axoral degeneration, and a reduction in the number of large and medium diameter fibers with, by comparison, little loss of the unmyelinated fibers.

This report strongly suggests that the neuropathy of acute intermittent porphyria is the result of a metabolic injury to the motoneuron, motor axon, or both, but not a primary injury to the Schwann cell or myelin sheath.

\section{Sensitization to Peripheral Nerve P2 Protein in the Guillain-Barré Syndrome}

William Sheremata, Susan Colby, Y. Karkhanis, Edwin H. Evlar. Montreal

The Guillain-Barré syndrome (GBS) has been postulated as a disease resulting from hypersensitization to constituents of peripheral nervous tissue (PNS). Study of experimental allergic neuritis (EAN) as an experimental model has provided data demonstrating a convincing analogy between these entities.

Both GBS and EAN demonstrate similar pathology with perivenular lymphocytic infiltrations in nerve roots, and root ganglia, early in disease. DNA synthesizing lymphocytes ("immunoblasts") have been found in the peripheral blood of both. Arnason has shown that lymphocytes from both EAN and GBS produce demyelination in rat trigeminal ganglion cultures. In other studies, we have shown delayed hypersensitization to crude extracts of PNS in both, and to crude $\mathrm{PH}_{3}$ extract of nerve in EAN. The isolation of a neuritogenic myelin basic $\left(P_{2}\right)$ protein by Brostoff et al has prompted us to investigate possible hypersensitivity to this antigen in GBS. 
The Thor-Rocklin technique of macrophage migration inhibition factor (MIF) assay was used to assess delayed hypersensitivity to rabbit $\mathrm{P}_{2}$ protein and to a partially clarified homogenate of human peripheral nerve. Twenty-four assays in $7 \mathrm{GBS}$ patients, 10 in other polyneuropathies, 10 in subjects with multiple sclerosis and 14 in normal controls were obtained.

Normal subjects gave a mean migration index of $107 \pm 7.8$ for $\mathrm{PN}$ and $103 \pm 7.2$ for $\mathrm{P}_{2}$. GBS patients with acute illness, not on steroids, gave means of $72 \pm 12$ and $74 \pm 8.7$ respectively. Subjects with other polyneuropathies gave means of $111 \pm 6.1$ and $102 \pm 10.6$ respectively. Multiple sclerosis patients values were $115 \pm$. 8.1 for $\mathrm{PN}$ and $105 \pm 6.4$ for $\mathrm{P}_{2}$.

Only subjects with GBS showed hypersensitivity to either purified $\mathrm{P}_{2}$ protein and to crude human $\mathrm{PN}$ antigen. All subjects with acute disease, not on steroids, showed evidence of delayed hypersensitivity to both antigens. Moreover, the degree of sensitization to either antigen was equivalent. Good correspondence of values with either antigen was seen in all groups of patients. Hypersensitization to a pure antigen with demonstrated neuritogenic potential has been demonstrated in human disease for the first time.

This finding lends support to the concept that GBS results from hypersensitization to an antigen in peripheral nervous tissue, and further suggests that this antigen is a PNS basic myelin protein.

\section{Myotonia Associated with Small Cell Carcinoma of the Lung \\ J. G. Humphrey, M. E. Hill, A. S. Gordon and W. Kalow, \\ Toronto}

A 60-year-old man presented with a six-week history of stiffness of gait and difficulty in opening and closing his hands for three weeks. His family history was negative. There was no history of previous muscle stiffness or drug ingestion. Examination showed myotonia of the face and hands, with percussion myotonia of tongue, thenar and limb muscles. Marked stiffness occurred on elevation of the arms and walking with improvement during activity. Muscle bulk was normal and no weakness found. Reflexes were depressed to absent and sensation normal. A hilar mass was seen on chest $x$-ray. Biopsy of a mediastinal lymph node showed anaplastic small (oat) cell carcinoma. Radiation was given with resolution of the hilar lesions.

Electromyography revealed high frequency discharges following contraction for four to ten seconds. Spontaneous and insertional rhythmic monphasic and diphasic complexes with frequencies of 100 to $300 / \mathrm{second}$, amplitudes of $100 \mathrm{uV}$ to 1.0 $\mathrm{mV}$, and durations of $2-5 \mathrm{msec}$ were recorded from many muscles. Considerable variation occurred in the discharge patterns of the spontaneous discharges with some starting and stopping abruptly while others did wax and wane in frequency and others occurred in short abrupt bursts. Motor unit potentials and repetitive nerve stimulation were normal. Muscle biopsy showed scattered small fibers. In vitro muscles produced contracture in a succinylcholine bath similar to that seen in muscle from familial myotonias. Serum and muscle extracts from the patient injected into rats produced no abnormality.

The myotonia was alleviated by quinine sulphate with only minimal myotonia being detected clinically or by electromyography. Subsequently the myotonia subsided spontaneously and completely within six months despite the development of widespread metastatic carcinoma.

\section{${ }^{3} \mathrm{H}$-Leucine Incorporation into Myofibrils of Normal and Dystrophic Mouse Skeletal Muscle}

George Monckton and Halyna Marusyk, Edmonton

The incorporation of ${ }^{3} \mathrm{H}$-leucine into normal and dystrophic mouse skeletal muscle before and after treatment with glycerol was investigated. Litter mate pairs of the Bar Harbor strain 129 $\mathrm{Re} / \mathrm{Jdy}$ were injected intraperitoneally with ${ }^{3} \mathrm{H}$-leucine and the erector spinae and sartorius muscles removed. Half of the muscles were treated with glycerol according to the method of Nihei (1973) and half were not. The muscles were then processed for light and electron-autoradiography and scintillation counting.

There was a significant decrease of leucine incorporation into both normal and dystrophic glycerinated muscle. The most marked decrease was in dystrophic glycerinated muscle. Glycerination is observed to disrupt cell membranes, hence rendering them more permeable, but leaving the contractile apparatus intact (Szent-Gyorgyi, 1949, 1951) (Bendall, 1969) (Rome, 1971).

It has been shown that there is an accelerated rate of amino acid incorporation into dystrophic mouse skeletal muscle, especially in regions where the sarcoplasmic reticulum is most prominent (Monckton, 1971). Nihei (1971) showed that there is very little amino acid incorporation into myosin in dystrophic mouse muscle.

It can be concluded that the excess amino acid incorporation occurs into non-contractile protein, supporting the view that myosin synthesis is reduced in mouse muscular dystrophy.

\section{Years After! Sequelae From Nutritional Polyneuropathy in Canadian Ex-POWs}

\section{J. Romine and A. Aguayo Montreal}

Many young healthy Canadian soldiers were imprisoned in Hong Kong and Japan during World War II. During the 44 months of their captivity these men suffered dietary restrictions and most prisoners developed a polyneuropathy. Neurologic clinical features and pathologic changes were documented soon after the war by Miller Fisher (Canad. Service Med. J. 11: 157-199, 1955). The present study was aimed at determining the long-term effects of nutritional deprivation upon the peripheral nervous system.

Twenty-five ex-POWS were studied clinically and by EMG and nerve conduction tests. Subjects selected had no post-war history of alcoholism or of diseases known to cause neuropathy. Twent $y$-one out of the twenty-five complained of sensory symptoms. These symptoms were described as "burning feet" in thirteen, a syndrome of "restless legs" was present in five. Four patients described recurrent spontaneous "shocklike" pains in the limbs. Only two complained of permanent numbness or of pins and needles in the feet. Neurologic examination revealed abnormalities in fifteen patients; slight atrophy and weakness of foot muscles in four, and diminished ankle jerks in four. Sensory loss was demonstrated in thirteen patients, it was mild and usually involved all modalities. Motor conduction velocities were usually within the normal range but more than half of these patients showed abnormalities of sensory conduction.

These findings indicate that sensory abnormalities and less commoniy motor deficit can be persistent sequelae of the polyneuropathy caused by a single period of nutritional deprivation. 


\section{Contractile Properties and Recruitment Order of Human Motor Units in Neuropathies and Motor Neuron Disease}

\section{R. G. Lee, R. B. Stein and H. S. Milner-Brown Calgary}

The contractile and electrical properties of motor units in the first dorsal interosseous muscle of the hand have been studied using recently developed techniques in 31 patients with ulnar neuropathies and motor neuron disease (amyotrophic lateral sclerosis). Among patients with unilateral pressure or entrapment ulnar neuropathies, there was a tendency for the twitch tensions for single motor units to be smaller while the surface EMG amplitudes were generally larger in the affected hands. Very large EMG amplitudes but normal size twitch tensions were observed among the motor neuron disease patients, indicating that in general motor units enlarged by sprouting are less efficient contractile units than units of normal physiological size.

Two years after surgical repair of a unilateral complete severance of the ulnar nerve, the twitch tensions increased to normal size. However, the normal orderly pattern of recruiting motor units of increasing size during increasing voluntary contractions were irretrievably lost. Among patients with pressure or entrapment neuropathies and with motor neuron disease, the normal orderly pattern of recruiting motor units was always retained. Similarly, in patients with motor neuron disease (amyotrophic lateral sclerosis), the orderly pattern of recruitment was not disrupted.

\section{Scientific Session - General Papers}

Chairmen: Dr. W. D. Stevenson, Dr. H. B. Dinsdale

\section{Electroencephalographic Evidence of Tolerance To and Dependence On Alcohol}

\section{R. G. Perrin and K. E. Livingston Toronto}

The acute effects of alcohol are a matter of widespread individual experience. Neurologically they have been characterized in terms of electroencephalographic changes in both animals and man.

The sequellae of acquired tolerance to alcohol are frequently encountered in clinical practice. Reliable E.E.G. evidence of acquired tolerance to alcohol has however not been previously described.

Using chronically-implanted, freely-moving cats, electroencephalographic changes were obtained showing tolerance to and dependence on alcohol.

These observations could have important clinical applicability, providing a precise indicator of withdrawal crisis.

\section{Diagnosis, Early Detection and Management of Surgical Lesions of the Chiasm}

\section{W. J. Horsey, Henry Berry and B. Gardner-Maher Toronto}

The common lesions which involve the chiasm produce their effects by compression and may present with unilateral or bilateral visual disturbance. The visual defects may be classified into four types; namely the syndromes of the anterior chiasmal angle, of the body of the chiasm, the optic nerve and of the posterior chiasmal angle. The commonest abnormality is unilateral optic atrophy with central scotoma and early depression of the contralateral temporal field (anterior chiasmal angle syndrome). A series of 43 patients with visual field defects due to sellar and parasellar lesions (excluding giant aneurysm) drawn from the Neurology and Neurosurgery Services at St. Michael's Hospital was reviewed.
Visual disturbance was the commonest presenting symptom often associated with headache or endocrinological failure. Diplopia was rarely encountered.

A normal sella was encountered in only 2 of the 26 patients with pituitary adenoma. A normal sella was the characteristic finding in patients with meningioma and glioma. The air study was reported as normal in one patient with chromophobe adenoma and in one patient with craniopharyngioma. The air study was predictably normal in the two patients with radiation necrosis. The commonest angiographic finding with intrasellar lesions was a lateral displacement of internal cartoid arteries and elevation of the first portion of each anterior cerebral artery.

The selection of the method of surgical treatments depends upon the preoperative diagnosis. The certainty of the diagnosis and the details of the anatomical structure of the sella and paranasal sinuses play a part in this decision. Preferrably pituitary adenomas are attacked by the trans-sphenoidal route but if there is uncertainty of the diagnosis or of the feasibility of this approach, the subfrontal operation is used. Masses other than pituitary adenomas are explored via craniotomy.

Considerable visual recovery was seen in most of the patients with craniopharyngiomas and pituitary adenomas regardless of the operative technique employed. In the small number of patients with meningioma, good visual recovery was the exception rather than the rule.

Evaluation of CCNU (1- (2-chloroethyl)-3-cyclohexyl1-nitrosourea), Radiation, and a Combination for the Treatment of Astrocytomas, Grade III and IV

B. Weir, P. Band, R. Urtasun, D. McLean, G. Blain, F. Wilson, B. Mielke and M. Grace Edmonton

\section{Meningiomas Induced by X-Radiation}

\section{Derek Fewer, Harold Rosen and Gilles Bertrand Winnipeg}

The case reports of a brother and sister who presented with intracranial meningiomas 49 and 37 years, respectively, following irradiation of the scalp for tinea capitis are outlined. Both patients showed evidence of radiation necrosis of the scalp and cranial vault. Important reference is made at two recent articles from Israel which describe twenty-one similar cases. Background material on the radiation treatment of tinea capitis is briefly discussed. Relevant references from the neurosurgical and neuropathological literature show that considerable controversy still exists with regard to a causal relationship between radiation and intracranial tumors. We believe that these twentythree cases provide indirect but conclusive evidence that irradiation can induce intracranial meningiomas.

\section{Simian Decorticate Rigidity as a Laboratory Model of Human Spasticity \\ F. Gentili and R. Tasker Toronto}

Despite the volume of reported research, considerable controversy exists on the degree of muscular hypertonia to be expected from cerebral decortication, or indeed on the area of cortex whose removal is responsible for decorticate rigidity.

Though there is intense current interest in quantitative studies of human spasticity, little work has been reported on unsedated animal models of spasticity.

We have re-investigated the whole subject of decorticate rigidity in the squirrel monkey, first to identify the minimal cortical region whose removal will produce spasticity, second to produce a laboratory model that simulates the clinical 
condition and with which to study spasticity. Spasticity has been characterized clinically and studied in a quantitative way using the integrated evoked EMG technique in which the slope of the curve of the evoked integrated EMG, plotted against the rate of muscle stretch is proportional to the degree of spasticity.

Over 25 monkeys have undergone various combinations of cerebral cortical ablations. We have documented both by careful clinical assessment as well as by photographs and movies, characteristic neurological deficits following removal of different cortical areas.

Hypertonicity of any significant degree does not result from unilateral ablations, no matter how extensive, of areas 4, 6 and supplementary motor area. Only bilateral ablations of area 4 and supplementary motor area result in marked hypertonicity similar to that seen in man. The increased muscle tone affects certain muscle groups more than others. Movies, clinical observations, quantitative measurements of tone, and response to static and dynamic stretch will be presented for the different preparations which were studied up to 2 months postoperatively.

In particular, the findings after unilateral and bilateral removals including and sparing area 4 and after unilateral and bilateral removal of the supplementary motor area will be presented.

\section{Adult Aqueduct Stenosis}

\section{R. Bennett, J. D. R. Miller and P. B. R. Allen Edmonton}

Eleven cases of aqueduct stenosis in patients over the age of 15 were collected in the period 1952 to 1973 at the University of Alberta Hospital. The condition was found to be more frequent in males and to present with non specific headache and low grade papilledema in the majority of cases. These symptoms were not considered sufficiently specific to allow a diagnosis on clinical grounds alone. Diagnois was made by X-ray contrast studies in each case. The possible role of trauma, infection, and congenital anomaly in the etiology is discussed, and the hazard of postponing surgery following ventriculography is emphasized.

\section{Intravenous Heparin in the Acute Treatment of Cluster Headache}

\section{Robert F. Nelson Ottawa}

Many forms of therapy have been recommended for the treatment of cluster headache. Prophylactic therapy includes methysergide (Sansert), ergotamine tartrate, corticosteroids and BC-105 (Sandomigran). Histamine desensitization which had been the classical form of therapy is still used by many. Therapy of the acute attack has been confined principally to ergotamine compounds with the most rapidly absorbed routes being preferable. Oxygen has been advised by Alvarez and by Horton and is certainly useful if available.

Thonnard-Neumann in 1969 demonstrated the effect of heparin on basophil counts from ear lobe in patients suffering from classical migraine. From his studies one might anticipate that heparin might be even more useful in treating cluster headache attacks.

The present report is on a preliminary study on the use of intravenous heparin in 12 patients suffering from cluster headache and 4 suffering from classical migraine. In the former group, spontaneous daily attacks had been occurring for at least a week. Six of 3 patients were observed during spontaneous attacks and all during attacks induced by sublingual nitroglycerin and in one by subcutaneous histamine. Untreated attacks ran a course of 45 minutes to 4 hours.
In treated attacks the patients were given $5,000-10,000 \mathrm{u}$ heparin as a single intravenous injection five minutes after onset of pain. In 5 patients $50 \%$ relief was obtained in 2-15 minutes and $100 \%$ relief in 5-30 minutes, and the mean duration of pain in all 12 patients was less than 25 minutes compared with a mean of 52 minutes for untreated attacks.

In one histamine-induced attack, the headache continued for 60 minutes. Two of the 4 classical migraine sufferers received marked relief within half an hour.

The possible mechanism of action will be discussed in relation to present knowledge of platelets, histamine and serotonin in headache mechanism.

\section{Analysis of 128 Patients with Angiogram in Acute Head Injury}

\section{P. Cinesi, J. D. R. Miller, M. Grace and T. N. Ayers Edmonton}

This paper has as its main objective a detailed computerized analysis of a total of 128 patients, admitted to the University of Alberta Hospital during the period 1970-1972 with the diagnosis of acute, severe head injury and who required angiographic studies.

In this analysis the role of angiogram was stressed, and an evaluation of the accuracy of this diagnostic tool in relation to several parameters received primary consideration. The angiographic studies were broken down into normal and abnormal and the latter subdivided into three major categories (extracerebral lesions, intracerebral lesions and brain stem lesions). The parameters with which the results were compared include: age, sex, presence or absence of lateralising signs on admission, the state of consciousness on admission (stupor, light coma and deep coma) and finally the type of accident responsible for the head injury (motor vehicle accidents, falls and assault).

In the assessment of the prognostic significance of each of these parameters, including the angiogram, the 128 patients were divided into four major categories of clinical-neurological condition on discharge viz: normal, minor disability, major disability and death, and the statistical analysis performed.

Finally the accuracy of angiography, whenever possible was tested in relation to diagnosis confirmed either by surgery or autopsy or a combination of both.

As might be expected, the state of consciousness on admission was significant $(\mathrm{P}<005)$ in relation to the condition on discharge, only $7 \%$ of patients admitted in stupor dying, whereas $57 \%$ of patients admitted in deep coma died, $29 \%$ suffered major disability and only $3 \%$ were discharged in normal condition.

An unexpected finding was that the condition on discharge bore no statistical relationship to the presence or absence of normal angiogram on admission.

\section{Friday, June 21, 1974 - Morning Session}

Scientific Session - Symposium II - Clinical and Laboratory Studies of Subarachnoid Haemorrhage

Chairmen: Dr. J. G. Stratford, Dr. J. C. Richardson

Address From Distinguished Guest of the Congress

Dr. Kristian Kristiansen

"Clinical and Neuroradiological

Studies of Subarachnoid Haemorrhage", 


\section{A Study of the Rate of Growth of Intracranial Aneurysms}

\section{J. M. Allcock and P. B. Canham London, Ontario}

Little information is available as to the rate at which intracranial aneurysms change in size. We have studied the records of 67 patients on whom angiography was performed more than once, and in whom there was a change in the size of the aneurysm. As some patients had more than one aneurysm, 82 in all are included. The intervals between the angiograms ranged from a few days to ten years.

In the majority, the sac became larger, but in a few it diminished in size, and these are also discussed.

We must acknowledge that what we see on the angiogram may not tell us the full size of the sac, as it may be filled with thrombus to a greater or lesser extent. The other major problem is that one cannot be sure when the aneurysm started to develop, so that one does not know at what point on the growth curve one is looking.

However, within the limits of the figures available, we are attempting to produce an estimate of the rate of growth of the sac, particularly with respect to its size when first demonstrated, and to see what correlation there is between the change in size and the clinical state.

\section{Intra-Operative Angiography in Aneurysm and Cerebral Angioma Surgery}

\section{Emile Berger and Marina Kyriazidou Montreal}

Visual verification at the time of clipping, even through the surgical microscope, does not always imply adequate obliteration of the aneurysmal sac nor absence of impaired flow in the parent vessel (Drake, G. C. and Allcock, J. M. Postoperative Angiography and the "Slipped Clip." J. Neurosurg. 39, $683-689,1973$ ). For these reasons the authors have been using intra-operative angiography immediately following clipping with the patient still on the operating table and the head open, a pre-operative angiogram having been done before the craniotomy incision.

This procedure permits us to ascertain if clipping is adequate and blood flow unimpaired. 10 to $12 \mathrm{cc}$ 's of $50 \%$ Hypaque is injected through an indwelling catheter and x-rays taken.

Even if coagulation of the aneurysmal neck followed by clipping and opening of the sac is performed, intraoperative cerebral angiography still provides useful answers concerning pre- and post-clipping spasm and post-operative clinical course. No direct correlation was found.

A total of 11 aneurysms and 4 angiomas were studied in this way.

A word of caution should be sounded. The fact that an aneurysm does not fill following clipping as evidenced by intra-operative arteriography, is not an absolute guarantee that such a clip might not slip at a later date. Two cases will be shown where control angiograms 14 days after the clipping revealed that the clip had slipped and the aneurysm was filling again. In both these cases the aneurysm had not been coagulated and/or opened.

\section{Spasm of Cerebral Arteries Following Subarachnoid Haemorrhage: Experimental and Clinical Observations}

\section{S. J. Peerless and M. J. Kendall Vancouver}

Using the fluorescence histochemical technique of Falk and Hillarp for noradrenaline and a modification of Koelle's method for acetylcholinesterase, the adrenergic and cholinergic components of the cerebrovascular and retinal vascular innervation apparatus has been examined in rabbits, rats and man following subarachnoid haemorrhage.

The loss of catecholamine fluorescence from the vascular neuronal plexus and inhibition of the normally powerful uptake mechanism of catechols in adrenergic nerves occurs after subarachnoid haemorrhage and persists for up to 8 weeks. Furthermore, there is marked increase in cholinesterase activity in the cholinergic nerves and muscle and a striking increase in the uptake of free catechols into the smooth muscle of the arterial wall.

In that noradrenaline is known to cause necrosis of smooth muscle and electron micrographic observations of human and animal cerebral vessels following subarachnoid injection of blood or noradrenaline has demonstrated myonecrosis, this study suggests that subarachnoid haemorrhage may alter the metabolism of the wall sufficiently to cause structural changes in muscle and thus be responsible for the prolonged reactive vascular narrowing.

Experimental and Clinical Evidence Bearing on the Prognostic Importance of Angiographic Spasm in Subarachnoid Haemorrhage

B. K. Weir, K. C. Petruk, D. Boisvert, and C. Rothberg Edmonton

\section{The Apparent Inefficacy of Dibenzyline in the Treatment of Cerebral Vasospasm A Review of Clinical Experience \\ G. G. Ferguson and C. G. Drake London, Ontario}

Panel On Vasospasm

Chairman: Dr. K. Kristiansen

J. D. R. Miller, Edmonton

Radiological Assessment

L. Y. Yamamoto, Montreal Mechanisms

E. W. Peterson, Ottawa Treatment

OPEN DISCUSSION

Friday, June 21, 1974 - Afternoon Session

Scientific Session I - Canadian

Association For Child Neurology

Chairmen: Dr. B. G. Lemieux, Dr. R. P. Humphreys

\section{Tay Sachs Screening Program in a French Canadian Population: Suggestive Evidence for Polymorphism of the Tay Sachs Gene}

Eva Andermann, Charles R. Scriver, Raynold Gold, Leon Wolfe, Georges Patry, Raymond Lafontaine, Guy Geoffroy, Frederick Andermann Montreal and Quebec City

In the past few years, we have ascertained seven French Canadian families with 12 children showing the clinical features of Tay Sachs disease. Enzymatic confirmation was obtained in all seven families, either in the probands or in their parents if the probands had died before hexosaminidase determinations became available. In five families, the enzymatic features were indistinguishable from classical Tay Sachs disease, whereas in two families, the enzymatic studies revealed Sandhoff's dis- 
ease. The Tay Sachs families originate mainly from a deme on the north and south shores of the St. Lawrence River east of Quebec City, where the consanguinity rate is known to be elevated, whereas the Sandhoff families originate from the Eastern Townships region of Quebec. The clinical data and pedigrees of these families have previously been reported.

We have undertaken a carrier detection program in the extended families of the Tay Sachs patients, which will include over 1,000 individuals. A serum sample is obtained on each individual tested. The hexosaminidase $\mathrm{A}$ and $\mathrm{B}$ determinations are performed by the automated method of Delvin et al. (1974). The values are plotted by a new method based on Bayes' theorem which distinguishes between carriers and normal homozygotes (Gold et al., 1973).

To date, 650 individuals have been tested. For 242 individuals analyzed, excluding obligate heterozygotes, the observed heterozygote frequency was $16.5 \%$, as compared with an expected frequency of $14.6 \%$, based on genetic hypothesis. The frequency of heterozygotes in relatives up to second-degree cousins of the proband was 39 out of $149(26.2 \%)$, whereas that in more distant relatives was only 1 out of $93(1.1 \%)$, and this difference was highly significant. The expected frequency of heterozygotes for the region tested based on the number of affected cases, birth rate and population of the region, was calculated to be $2.9 \%$, similar to that found in Ashkenazi Jews, as compared to only $0.3 \%$ found in a large French Canadian control group from the Montreal region.

The density distributions of hexosaminidase $A$ versus $B$ in normal homozygotes of the screened population were found to differ from the corresponding values in French Canadians from the Montreal region. These findings suggest the possibility that the gene(s) controlling hex A and B in the deme from which our families originate is (are) different from those in the control French Canadian population. Similarly the mutant allele in this deme might be different from that in Ashkenzai Jews.

\section{Ataxia Telangiectasia}

\section{G. G. Hinton and F. R. Sergovich London, Ontario}

A five-year-old girl presented with recurrent otitis media which began at three months of age. Physical examination showed delayed development, ocular and auricular telangiectasia and an unsteady gait.

Unlike the usual immunoglobulin deficiency of $\operatorname{IgA}$, she showed instead complete absence of IgG with normal IgA and reduced $\mathrm{IgE}$ levels.

Cultured peripheral lymphocytes showed a high frequency of chromosome breaks exchanges and polyploidy. In virtually all cells a marker chromosome was present which could be identified as a broken number 14 translocated on to another acrocentric chromosome.

It is suggested that this chromosome number 14 abnormally is linked to the immunological deficits and clinical features of ataxia telangiectasia.

\section{Hereditary Ataxia with Immune Deficiency and Alpha-Fetoproteinemia in Absence of Telangiectasia}

A. H. Rajput, E. M. Ashenhurst, W. E. Decoteau, B. Rozdilsky Saskatoon

A 53-year-old male (D.S.) with long history of incoordination was found to have severe cerebellar ataxia, choreiform movement, and posterior column dysfunction when first seen at the age of forty-four. Nine years later his condition deteriorated and in addition to above, he developed peripheral neuropathy. He had no evidence of telangiectasia. His sister (E.S.) who died at the age of fifty-five of carcinoma of the breast, was diagnosed to have spino-cerebellar degeneration. She had no telangiectasia. The patient's one brother (J.S.) with no neurological abnormalities, had a daughter (C.S.B.) with full-blown picture of ataxia telangiectasia (A.T.) who died at the age of twentyone. She was found to have immunologic abnormalities often associated with ataxia telangiectasia, including selective IgA deficiency and evidence of defective cell-mediated immunity.

Immunological and biochemical studies performed on the patient (D.S.) revealed many typical abnormalities seen in ataxia telangiectasia, including selective IgA deficiency, defective cell-mediated immunity, abnormal glucose tolerance test, and most importantly, an elevated level of serum alphafetoprotein. Alpha-fetoprotein elevation has been found in all cases of ataxia telangiectasia by Waldman.

This study is of interest for the following reasons: (1) It demonstrates that neurological syndrome like A.T., associated with immunologic and biochemical features of ataxia telangiectasia, may be seen in the absence of telangiectasia. (2) The syndrome can be associated with greater longevity than has been previously described in ataxia telangiectasia. (3) The syndrome appears to be more severe in subsequent generation. (4) The usual mode of inheritance in ataxia telangiectasia is believed to be autosomal recessive; whereas in this study it appeared to be autosomal dominant type.

\section{Remission in Subacute Sclerosing Panencephalitis (SSPE) with Antiviral Therapy \\ Robert F. Nelson Ottawa}

SSPE is a progressive disease of the nervous system for which there is no recognized cure. The vast majority $(90 \%)$ of cases are dead within 24 months of diagnosis: only a few cases have been reported to have survived the disease, usually in a deteriorated state.

Measles virus has been implicated in the etiology and this offers hope that an antiviral agent might be therapeutic and possibly curative. Deoxyuridine derivatives, amantadine and poly I-C (an interferon-inducing agent), have all been used but benefit has been questionable.

In the present report a combination of amantadine and a series of poly I-C infusions have been given to a boy diagnosed as having SSPE in July 1970 on the basis of clinical picture and verified by EEG, CSF electrophoresis and measles antibody levels. A remarkable remission seems to have occurred and after $3 \frac{1}{2}$ years he is now attending opportunity classes at school but is left with residual left spastic hemiplegia. Seizures and myoclonic jerks are no longer seen and EEG has returned almost to normal.

Although poly $\mathrm{I}-\mathrm{C}$ is an interferon-inducing agent, no significant interferon response was detectable in CSF or blood following infusion, but measles antibody levels have declined slightly during this stage of remission. The possibility of a spontaneous remission cannot be excluded and 3 other cases similarly treated have shown less satisfactory results.

Similar cases reported in the literature will be reviewed and the patient's clinical features illustrated with a short film taken serially throughout his illness.

\section{Electroencephalographic Correlates of Hydrocephalus in Infants and Young children}

Sherrill J. Purves and Morton D. Low Vancouver

There are few reports in the literature of systematic studies of the EEG of infants and young children with hydrocephalus. 
What reports there are have conveyed an incomplete picture and some published correlations have been contradictory.

This study was undertaken to determine the nature of the EEG correlates of hydrocephalus and whether electrographic findings could be related to etiology, degree of severity or stage of treatment of the clinical condition.

Several possibilities for the application of EEG assessment in hydrocephalus have been suggested in other literature, including the possibility that EEG might be useful in a determination of shunt patency and as an ancillary aid in the diagnosis of arrested hydrocephalus. It is clear that in the presence of complications such as seizures, it would be important to know what electrographic abnormalities are likely related to the primary condition of hydrocephalus and which abnormalities are likely due to developing complications.

To attempt to answer these questions we have conducted a retrospective analysis of EEG's done on hydrocephalic children in the EEG Department of the Vancouver General Hospital between 1969 and 1973. Ventriculographic or pneumoencephalographic confirmation of the diagnosis was obtained in all cases.

The series includes fifty patients and we obtained an average of two EEG's per patient. Fifty-five percent were infants less than one year of age and more than ninety percent were recorded from children less than five years of age.

The most common electrographic findings were in part related to the age of the patients, with the children less than one year of age showing most commonly an excess of scattered sharp transient activity and asymmetries of background rhythms while the record of the older children (age one to ten years) most commonly showed paroxysmal generalized slow dysrhythmias and asymmetries of background rhythm.

These findings will be discussed with regard to the EEG's findings before and after shunting and for groups of various etiologies.

\section{Thymectomy in Myasthenia Gravis}

\section{H. A. Waisburg and E. G. Murphy Toronto}

Twenty-one cases of myasthenia gravis were seen at the Hospital for Sick Children, Toronto, from 1959 to 1973. Four had the transient neonatal form, six the localized form of juvenile ocular myasthenia, ten had the progressive generalized juvenile form and one the congenital form. The management of the latter eleven cases will be described in detail and their treatment with Thymectomy, Anticholinesterase and in two cases with ACTH will be assessed. The thymicpathology in relationship to the clinical features and progress will be assessed. The follow up of these patients (average 10 years 8 months) showed that five cases were asymptomatic and required no Anticholinesterase treatment and five cases improved with mild symptoms and controlled with medication. The congenital form did not respond too well to the Thymectomy but subsequently responded very well to ACTH.

\section{Spinal Dysraphism \\ F. B. Maroun, J, C. Jacob, W. D. Heneghan St. John's Newfoundland}

We have encountered a relatively large number of examples of spinal dysraphic states during the past five years. The apparent high incidence of these anomalies may, in part, be due to the awareness that there are invariably multiple anomalies representing spinal dysraphism in any particular case, and also to our location in the principal referral centre for pediatric neurologic problems in the province of Newfoundland and Labrador.

The presenting features may be overt i.e., in association with a myelomeningocele, which has been previously repaired; or may be subtle. In the latter situation the clinicial manifestations may be primarily cutaneous, musculo-skeletal (lower limbs) genitourinary or manifestations of cauda equina/lower spinal cord dysfunction. These modes of presentation will be illustrated.

The wide variety of lesions encountered at surgery will also be illustrated. These include: Neurodermal sinus, lipomata, fibrous bands, tethering of the conus and diastematomyelia.

\section{The Prevention of Status Epilepticus in Institutionalized Epileptics}

R. E. Masotti, C. Simons, J. R. H. Stewart Kingston

Parenteral diazepam (Valium) is recognized as the drug of choice in the emergency treatment of status epilepticus (SE) in adults (Wilson, 1968) children (McMorris and McWilliam, 1969) and neonates and infants (Smith and Masotti, 1971). In most cases, diazepam was used intravenously, but its value when given intramuscularly (IM) has been documented by Lalji (1967), McMorris (1969) and Ferngren (1974). This study reports the prophylactic use of IM diazepam given by the nursing staff to prevent SE.

In a long-stay hospital school for the mentally retarded, with an epileptic population of 300 , the average yearly incidence of admissions for SE to the Acute Hospital Unit was 26. There was a five-fold reduction to 5 cases yearly in the years 1971-1972, following the introduction of a prophylactic routine using IM diazepam after any single seizure lasting longer than five minutes or after any second seizure occurring within 24 hours. No complications have been identified from the program, and, since its inception, no deaths directly attributable to SE have occurred.

During the years 1967-1970, the epileptic death rate (60/1,000/year) was six times times that of the non-epileptic population. During the treatment period, (1971-1972) the epileptic death rate dropped dramatically and now approaches that of the non-epileptics. It suggests that $\mathrm{SE}$ and serial seizures had been contributing to some deaths in institutionalized epileptics.

We conclude that IM diazepam, administered by the nursing staff, is a reasonable, safe and effective method of preventing status epilepticus in institutionalized epileptics.

\section{Friday, June 21, 1974 - Afternoon Session \\ Scientific Session II - General Papers \\ Chairmen: Dr. F. Andermann \\ Dr. M. Low}

\section{The Role of the EMI Scan in Focal Epilepsy}

W. Feindel, R. Ethier, and L. Yamamoto Montreal

Computerized axial transverse tomography using the EMI scanner has given a new tool for the early detection and localization of lesions associated with focal epilepsy. Because of the speed, safety and simplicity of the method, there are fewer barriers to early examination and repeated examinations as viewed by either the patient or the doctor.

In addition, the level of information derived from the EMI scan provides a basis for decisions on admission to hospital for more extensive investigation or for following the patient outside the hospital with repeated scans. 
We have selected a series of patients who had focal seizures as a presenting or prominent feature of their clinical course. The site and nature of the lesion are described. Comparison with the findings from electroencephalography and radioisotope brain scans will be made.

In patients where surgical lesions were disclosed, the EMI scan was of particular value in giving the surgeon information on the exact topography of the lesion, Individual examples correlating the scans with the operative findings will be presented.

\section{The Differentiation between Cortical and Subcortical Epilepsies: an experimental and clinical study}

Kenneth E. Livingston, Robert S. McPhedran (Toronto) and Ronald J. Racine (Hamilton)

The experimental model of convulsive seizures induced by repeated low intensity stimulation of the amygdala, designated by Goddard as "kindling" provides many interesting analogies to clinical epileptic states.

In recent studies using this model, we have screened a number of drugs and have examined in detail the effects of three drugs on the kindling process - Diphenylhydantoin, diazepam, and procaine hydrochloride.

Diazepam in doses that produce minimal behavioral effects, markedly suppresses the electrical excitability of the amygdala so that electrographic and behavioral seizure development is blocked. In contrast to this marked sub-cortical effect, the administration of substantially higher doses of diazepam produces only minimal suppression of seizures induced by cortical stimulation.

In contrast to diazepam, procaine hydrochloride in doses that produce no behavioral effects, strikingly increases the electrical excitability of the amygdala, so that procaine treated animals are fully "kindled" before the control animals reach the behavioral seizure level. At the cortical level however, procaine at the same dosage produces marked suppression of electrographic and behavioral seizure activity.

Diphenylhydantoin produces effects that are very similar to procaine - facilitating the response to amygdalar stimulation, while markedly suppressing the responses to cortical stimulation.

In 1955 Peterson demonstrated that intravenous procaine blocked descending inhibitory influences from stimulation of the midbrain reticular formation. In 1957 French et al showed that a bolus of intravenous procaine blocked electrographic and behavioral seizures induced by stimulation of the Rolandic cortex in the awake monkey. More recently Livingston and Perrin have shown that intravenous procaine blocks the vagal response to baroreceptor stimuli.

On the basis of evidence that procaine blocked cortical seizure discharge we have been studying for the past 18 months, the effects of intravenous procaine in a group of patients with seizures that have been refractory to standard anticonvulsant medication.

The E.E.G. and clinical responses of these patients to intravenous procaine were not uniform, and were difficult to explain until the recent evidence from the "kindling" experiments became available. To date the clinical findings correspond quite well with the laboratory data, suggesting that it may be possible to "sort out" some of the complex seizure disorders on the basis of their acute response to specific pharmacological agents.

\section{Treatment of Experimental Focal Epilepsy by Subpial Vertical Cortical Incisions}

Jacques Duysens and Donald R. McLean Edmonton

The classical surgical methods for the treatment of focal epilepsy have the disadvantage of producing a functional deficit when strategic parts of the brain must be removed. A possible solution to this problem involves the use of subpial vertical cortical incisions isolating the epileptic area. This procedure is said to control the seizures without producing any functional deficit.

To test the efficacy of this method, subpial cortical isolation was performed on a cobalt-gelatine epileptic focus created in the motor cortex of cats. After epileptic activity was established, the focus of half the cats was isolated by subpial cuts, 2 $\mathrm{mm}$. deep, forming a $2 \times 2 \mathrm{~mm}$. square. The remaining cats had sham operations. Subpial cortical isolation obliterated the epileptic spike and the clincial seizures, whereas the sham operation had no effect. It is speculated that this effect was produced by reducing the neuronal mass available for hypersynchronization.

That no significant functional deficit followed this surgical technique was indicated by no change in paw preference or placing reflexes in the operated animals. The columnar organization of the cerebral cortex may account for this lack of surgical injury.

This approach to the problem of focal epilepsy is promising. Further research is needed to elucidate the optimal distance and configuration of the subpial incisions before this technique can find a wider application.

\section{The Outcome of Pregnancy in Epileptic Women}

Linda Dansky, Eva Andermann, Frederick Andermann, Allan Sherwin Montreal

In recent literature, an increased incidence of major congenital defects such as cleft lip and/or cleft palate, cardiac anomalies and microcephaly has been reported in newborns of epileptic mothers receiving anticonvulsant drugs during pregnancy (Speidel and Meadows, 1972). We have initiated at the Montreal Neurological Institute a retrospective and prospective study to elucidate the teratogenic risks of anticonvulsant medications.

A preliminary investigation into the marital and reproductive histories of 100 epileptic women and 100 epileptic men revealed a significant decrease in fertility in patients with seizure onset under 12 years of age; a significantly higher marital and reproductive rate in female versus male patients; an almost significant increase in frequency of perinatal deaths and major congenital malformations in the offspring of epileptic females as compared to those of epileptic males.

Detailed family and reproductive histories were then obtained from 54 epileptic women having at least one pregnancy. These women had 165 pregnancies, 114 on anticonvulsant medication during the first trimester. Seventeen of 134 viable offspring (12.7\%) had major congenital malformations. Fourteen of 88 offspring (15.9\%) of mothers on anti-convulsant medication were born with the following malformations: 6 congenital heart disease, 3 cleft lip, 2 ventral hernia, 1 hypospadias, 1 tracheo-esophageal fistula, and 1 microcephaly. The anticonvulsant drugs administered to these mothers included various combinations of diphenylhydantoin, phenobarbital. primidone, ethosuximide and tridione. Three of 46 offspring (6.5\%) of mothers not on medication had Sturge Weber syndrome, congenital dislocation of the hip, and congenital heart 
disease, respectively. There was no significant difference in seizure frequency and other maternal complications during pregnancy, or in family history of major congenital malformations between offspring with and without malformations.

For 17 pregnant epileptic women studied prospectively, monthly anticonvulsant drug levels were recorded and these were correlated withoutcome of pregnancy. Drug levels remained relatively constant throughout gestation and were comparable with fetal levels at term. No significant differences were found in mean anticonvulsant levels between mothers of normal and malformed offspring.

\section{Miliary Toxoplasmosis Presenting as Subacute Encephalitis in Adult}

\section{Young, M. C. Bach, R. M. Armstrong, J. R. Wherrett} Toronto

A 35-year-old man presented with a 3-day history of irrational behavior and incoherent speech which had developed during convalescence from an acute illness of fever, nausea and vomiting and headache beginning one week earlier. Neurologic examination revealed a febrile, confused, dyspractic man. Lumbar CSF contained $305 \mathrm{mg} \%$ protein and 6 white cells per $\mathrm{mm}^{3}$. In the absence of specific therapy, he deteriorated over the next 3 weeks in a fluctuating fashion, accumulating signs of widespread hemisphere and brainstem involvement until he could be roused only briefly by painful stimuli without psychological response. At this point, high titres of antibody to toxoplasma were reported (Sabin-Feldman Dye test: serum, 1:4,096; CSF, 1:64; IGM indirect fluorescent antibody test: serum 1:1,280). Coincident with sulphadiazine and pyramethamine therapy, gradual but sustained recovery occurred. Although neurologic features were predominant, systemic involvement was indicated by mild abnormalities of liver function and microscopic haematuria early in the course, eosinophilia, histological evidence of myositis and a striking skin eruption of irregular blanching macules tending to confluency as the neurologic condition worsened. Neither retinopathy nor lymphadenopathy were present. Although the organism could not be detected in biopsies of skin, muscle and brain, serologic studies and response to therapy support strongly the diagnosis of miliary toxoplasmosis. This form of a common and treatable infection is reported rarely but should be considered in the differential diagnosis of meningoencephalitis. Recognition of toxoplasma as an opportunistic agent in the immuno-suppressed host, suggests that the disease may be seen with increasing frequency in future. Features which should arouse clinical suspicion and laboratory means for early diagnosis will be discussed.

\section{A Neuropathological Study in a Case of Progressive Autonomic Failure (Shy-Drager Syndrome)}

Jacques De Léan, John H. N. Deck Toronto

\section{Hypothermia in Wernicke's Disease \\ J. T. Marotta, J. Bilbao Toronto}

In the last 2 years, four cases of profound hypothermia have been examined at St. Michael's Hospital. Each of these patients had good clinical evidence of Wernicke's encephalopathy. One of the four died and autopsy material will be presented.

A discussion of hypothermia, the hypothalamus and Wernicke's encephalopathy will ensue.

The incidence and treatment will be discussed.

\section{Jacob-Crentzfeld Disease (JC) with Atypical Familial Occurrence}

William Sheremata, Ilona Kerner, Stirling Carpenter, John McGovern Montreal

Familial occurence of Jacob-Creutzfeld disease (JC) has recently been recognized, but the finding of atypical illness in family members has not been reported. We have observed atypical illness affecting 3 members of a large family related to a pathologically confirmed case.

A 74-year-old merchant from Curacao found his business failing and complained of visual difficulty. Ophthalmological consultation failed to document visual impairment, but cortical blindness was present terminally. Gait difficulty appeared simultaneously, and preceded recognition of his dementia by 2-3 months. Dementia was global from outset, and was followed shortly by the appearance of myoclonus. Six months after onset, the patient was mute and bedridden with marked cerebellar tremor. After 3 months of dysphagia, and rigidity, and after 11 months of illness, he died. At autopsy, spongioform cortical degenerations typical of Jacob-Creutzfeld were found predominantly in the occipital lobes.

A 72-year-old sib developed progressive dementia and ataxia 12 months following onset of $\mathrm{JC}$ in his brother. Myoclonus appeared 6 months later. He is alive after one year, but is demented, and ataxic. His deficit seems to have reached a plateau.

After a one year absence and 4 months prior to his illness, the propositus met his 28-year-old daughter. Six weeks later, she developed depression, headache, and somnolence. CSF examination showed 200 lymphocytes. Recovery has been protracted, and marked by severe depression. A second daughter developed ataxia and incapacitating depression 4 months after her father's demise. Symptoms have gradually but incompletely remitted.

The present observations suggest that illness atypical of JC may occur in some individuals affected by the agent responsible for Jacob-Creutzfeld.

$$
\text { Friday, June 21, } 1974 \text { - Afternoon Session }
$$

Scientific Session III - General Papers

Chairmen: Dr. E. B. Hendrick, Dr. K. W. E. Paine

\section{Post-Discoidectomy Meningeal Cheloid}

S. N. Martinez and L. J. Papineau Montreal

\section{Lumbar Spinal Stenosis}

\author{
K. W. E. Paine
}

Saskatoon

Lumbar spinal stenosis may be developmental, degenerative or iatrogenic. Examples of the different types causing an entrapment neuropathy of the cauda equina will be discussed. The argument that spinal stenosis may follow spinal fusion or chymopapase injections will be illustrated by clinical studies and experimental animal studies. Recommendations regarding the method of surgical management of spinal stenosis will be made with the results in long term follow-up studies analysed in relation to the type of stenosis present and the operative procedures performed. A plea will be made for the necessity of recognizing the presence of spinal stenosis before undertaking any operative management of patients with a "lumbar disc syndrome." 


\section{Lumbo-Sciatic Syndrome Due To Extradural Venous Varices}

\section{Harold J. Rosen Montreal}

In the majority of patients with a significant and intracable lumbo-sciatic syndrome requiring surgical decompression, there is intraspinal and/or intraforaminal involvement of one or more nerve roots, or of the cauda equina itself. In most such cases, the radiculopathy is due to an intervertebral disc protrusion (acute or chronic, ruptured or bulging); to spondylotic confinement of the spinal canal at one or more interspaces; to developmental stenosis of the canal; or to a variable combination of these pathological conditions.

In the author's personal experience with approximately 1,500 patients operated for this condition, there have been 10 cases in which the major, or only, basis for the symptomatic radiculopathy has been the presence in the extradural space of a distinct and localized collection of venous varices, intimately related to the symptomatic nerve root. To the author's knowledge, this entity has not been previously delineated.

The clinical presentation, myelographic findings, and surgical pathology in these 10 cases will be described, and compared with those of the more usual lumbo-sciatic syndrome patient.

It is of interest that these extradural venous varices involved the L1-2 interspace once, the L2-3 interspace twice, the L3-4 interspace on three occasions, and the L4-5 interspace in the remaining four cases; the L5-S1 interspace was never the site of this particular condition. In contrast, the author's statistics, confirmed by those of many other observers, indicate that the more usual interspinal pathology leading to operation for the lumbo-sciatic syndrome involves the $L_{4}$ to $S_{1}$ portion of the spinal canal in approximately $95 \%$ of the cases.

\section{The Lumbo-Sciatic Syndrome in the Second Decade \\ J. Cartier Giroux and Toussaint A. Leclercq Montreal}

From 1958 to $1973,1,200$ patients were operated on for herniated lumbar discs. 45 patients were 21 years old or less. For this study, they were divided in two groups: Group A consisting of eleven cases between 13 and 18 years old and group B 34 cases between 19 and 21 years of age.

The syndrome of herniated lumbar disc in adults is well known. Its occurrence in younger patients is rare. The analysis of this series shows that the symptomatology is different from that in adults. Remarkable findings include:

-In both groups direct relationship with tranma is frequent and the number of males far outweights the number of females (5 to 1$)$.

- The interspace L5-S1 is more frequently involved than L4-5 in group A ( 7 to 1) as compared to group B where the number is the same at the two levels.

-Despite a marked pathology at operation, the neurologic examination shows no deficit. In group $A$, except for a positive straight leg raising test, the neurologic examination was normal in all cases, despite the fact that two had a ruptured disc and two an extruded disc. This feature is less marked in group B where neurologic deficits were found though less frequently than in adults.

The time elapsed between appearance of symptom and operation was long in many instances, probably because of hesitancy to consider the diagnosis in a young patient. Because of the excellent results in this age group, the procedure should not be unduly delayed.

\section{The Gluteus Medius Syndrome}

\section{William Pryse-Phillips St. John's, Newfoundland}

A syndrome of lumbo sacral pain and disability closely resembling that associated with prolapsed intervertebral disc is redescribed. The major clinical features include occurrence in both sexes mainly between 20 and 50 years of age; acute and later continuing chronic pain precipitated by an initial fall or unwonted exertion; the pain radiating from retro-iliac to centrolumbar and posterior leg regions; aggravation with rest, sitting, and lying in bed; improvement with walking, and standing and frequent clinical association with a depressive reaction. The signs include subjective sensory change not conforming to dermatomal distribution, generalized leg weakness with restricted hip flexion and abduction, normal deep tendon reflexes and marked point tenderness at the insertion of gluteus medius into the ilium. EMG and nerve conduction studies are invariably normal. Relief may be obtained by local anaesthetic injection with or without steroids but usually has to be repeated.

The clinical features of 12 patients are presented, all with a 1to 2-year history of this complaint. Usually initially diagnosed and treated for prolapsed intervertebral disc with negative myelography as part of the investigation prior to neurological referral. The genesis of the pain is discussed in terms of classic studies of referred pain with ligamentous and muscular injection of hypertonic saline and it is concluded that pain in the Gluteus Medius Syndrome is of similar origin following unusual contraction or tearing of the muscle in association with abnormal posture or trauma.

\section{Percutaneous Cordotomy For Intractable Pain Clinical-Pathological Correlation}

\section{H. W. K. Barr and J. J. Gilbert London, Ontario}

Twenty-two patients with intractable pain syndromes have been treated by cervical percutaneous cordotomy at the C1-C2 level using the Owl Percutaneous Cordotomy System. Although. the series is small, the results are encouraging, with complete relief of pain in fourteen and a significant improvement in another seven patients. The spinal cord from three cases is available for microscopic examination, two weeks, four weeks and three months following operation. Successful destruction of the spino-thalamic tract is noted in all three, plus destruction of the ventral spino-cerebellar tract.

After two weeks axonal swelling, demyelination and vacuolization are prominent. No inflammatory response is noted and astrocytic proliferation is minimal. After four weeks changes are similar, but with more astrocytic reaction. At the three month period astrocytic proliferation and macrophage infiltration are considerable and ascending spino-thalamic tract degeneration is evident. In two cases central chromatolysis of anterior horn cells is noted with destruction of ventral rootlets. In the patients studied three months post-operative, retrograde degeneration of the spino-thalamic tract and ventral spinal cerebellar tract is present to a level below C8. In one case the affected area of change has spread to involve a portion of the lateral cortical spinal tract.

In the co-operative patient, the percutaneous approach utilizing motor and sensory stimulation ensures accurate placement of the lesion in the lateral spino-thalamic tract.

\section{Selective Rhizotomy of Trigeminal Sensory Root By Thermocoagulation for Tic Douloureux} Ian Turnbull Vancouver

The surgical technique described by Sweet and Wepsic for selective thermocoagulation of the trigeminal sensory root for 
tic douloureux has been used by the author since 1970 on 35 patients. We have used a percutaneous cordotomy needle and electrode with a $5 \mathrm{~mm}$. exposed tip and consequently our technique differs from that of Sweet and Wepsic in that we are not able to monitor temperature during thermocoagulation. However, by making the lesion in incremental steps it is possible to control the amount of damage done to the root and to limit it largely to the desired division of the root. The thin wire electrode used to make the lesion would appear to have an advantage over the larger electrode used by Sweet and Wepsic in that we can tell whether we are in the root or merely alongside it by the threshold of response to stimulation which is used to localize the part of the root to be damaged. The operation has been highly successful in stopping tic douloureux. We have not been successful in every case in limiting the denervation to only loss of pain sensibility in the desired division of the trigeminal nerve. The results of operation will be described with regard to the degree of denervation achieved in each case. There has been no neurological morbidity outside of the trigeminal nerve and no operative mortality, although some of the patients have been seriously ill with unrelated diseases.

\section{The Effect of Dorsal Column Stimulation on the Somatosensory Evoked Response}

R. Graham Vanderlinden, R. D. Gordon Blair, and R. G. Lee Toronto

\section{Saturday, June 22, 1974 - Morning Session \\ Scientific Session - Prize Papers}

Chairmen: Dr. E. M. Ashenhurst, Dr. J. G. Stratford

\section{K. G. McKenzie Memorial Award Winning Paper}

Canadian Neurological Society Prize Essay:

\section{Schwann Cell Multiplication in Unmyelinated Nerve Fibers Fol-} lowing Experimental Crush Injury

\section{John S. Romine, Montreal}

While peripheral autonomic and sensory nerves consist predominatly of unmyelinated fibers, the understanding of basic pathologic reactions in these fibers is limited. Therefore, radioautography and electron microscopy were used to study the intensity and duration of Schwann cell multiplication in unmyelinated fibers after crush injury. Left cervical sympathetic trunks (CSTs) were crushed in 28 adult mice. Pairs of animals were sacrified at intervals from 1 to 21 days after injury. One hour prior to sacrifice each animal was given tritiated thymidine intraperitoneally. Labeled and unlabeled Schwann cell nuclei were counted in longitudinal sections of CST and the labeling index (LI) was calculated for each nerve.

At the level of crush, the labeling index rose to a mean value of $22.5 \%$ on the 2 nd day after injury and returned to $1 \%$ by the 9th day. However, 2-3 mm. distal to the level of crush, the LI only reached a peak of $2.5 \%$ on the 2 nd day and declined to normal after the 9th day. Electron microscopy confirmed that the majority of increase in cell muclei at the area of crush was due to Schwann cells.

Possible explanations for the difference between labeling at the crush site and in the distal nerve were discussed and the low level of Schwann cell multiplication in the distal CST was compared to results from previous quantitative studies.

\section{Scientific Session I - General Papers}

Chairmen: Dr. E. M. Ashenhurst, Dr. A. J. Hudson

\section{Dramatic Effect of Methysergide on Myoclonus \\ Paul Bédard, Rémi Bouchard Québec}

\author{
Monosymptomatic Respiro-vocal Tremor \\ V. C. Hachinski, Toronto \\ I. V. Thomsen, N. H. Buch, E. Skinhøj \\ Copenhagen, Denmark
}

Three elderly women, with marked insidiously progressive voice tremor with no other neurological symptoms and negative family histories, were investigated.

All had a $4-5 \mathrm{~Hz}$ respiratory tremor in expiration and, to a lesser degree, in inspiration; and all had vocal tremulousness synchronous with their respiratory irregularity. Articulation of phonemes was normal. In one patient the remainder of neurological examination was entirely normal; in another there was minimal head titubation; and in the third there was minimal $71 / 2 \mathrm{~Hz}$ tremor in the left thumb and index finger.

Simultaneous speech and vocal air pressure recordings were determined, and cinematographic studies of the vocal apparatus and diaphragm were carried out.

It is suggested that these cases represent basically an action tremor of respiration, that they belong to the spectrum of essential tremor and hence may become amenable to treatment with propanolol.

\section{Anatomical Basis of Autonomic Dysfunctions in Parkinsonism}

\section{A. H. Rajput, B. Rozdilsky Saskatoon}

Severe autonomic dysfunctions have been well documented in Shy Drager syndrome and abnormalities of lesser degree characterized by sialorrhea, seborrhea, constipation, excessive sweating, etc., have been demonstrated in nearly 50 percent of idiopathic Parkinsonism. The major lesion in Shy Drager syndrome is in the preganglionic autonomic cells, but no definite anatomical basis has been established for autonomic abnormalities in idiopathic Parkinsonism. On the basis of physiological and pharmacological studies it has been postulated that major pathology responsible for these abnormalities is central (hypothalamic). It is well known that the interpretation of such studies in man is not accurate. There is very little support from pathological studies to this hypothesis as well.

We have studied five idiopathic Parkinson's Disease patients and one age-matched control clinically and pathologically, Historic details about autonomic functions, degree of seborrhea, sweating patterns, and routine and intra-arterial blood pressure were recorded before treatment with L-Dopa and repeated while the patients were on treatment, Clinical features in different patients included: (1) severe diffuse autonomic dysfunction; (2) sweating crisis and oculogyric crisis; (3) postural hypotension on L-Dopa only; (4) no autonomic dysfunctions prior to or on L-Dopa therapy.

Histological examination of entire central nervous system including spinal cord and light and electron microscopic studies on sympathetic ganglia were done in all patients. In addition to well recognized changes in pigmented nuclei in the brainstem, all patients had some degree of pathological changes in the sympathetic ganglia. These changes were most marked in severe dysautonomia and least when no clinical autonomic dysfunctions were present at any time before or on L-Dopa therapy. Only one patient had hypothalamic pathology. The clinical picture of this patient was characterized by sweating crisis and oculogyric crisis in addition to classical Parkinsonian features. 
We conclude that the site of major lesion responsible for autonomic dysfunctions in idiopathic parkinsonism is the autonomic ganglia. Pathological changes in the hypothalamus are rare and are not the cause of autonomic symptoms in untreated or treated Parkinsonism in most cases. Details of clinical features and pathological findings will be presented.

\section{The Effect of Chronic Levodopa Therapy on Dopa Metabolism}

\section{Harold Mars Cleveland, Ohio}

Despite the significant benefit obtained by a majority of Parkinsonian patients to levodopa therapy, some have experienced a progressive loss of therapeutic effect after a few years. The chronic administration of a drug frequently results in increased activity of metabolizing enzymes. Investigations of the systemic decarboxylase system following chronic levodopa have yielded contradictory results. The effect of $250 \mathrm{mg}$ levodopa alone and combined with $50 \mathrm{mg}$ carbidopa (MK-486; alpha-methyl-dopa hydrazine) was investigated in 15 treated patients and 10 dopa-naive controls. Blood was drawn at 0,60 , 120 and $240 \mathrm{~min}$ following drug(s) administration, and assayed for dopa and homovanillic acid (HVA). Plasma values were integrated by manual planimetry and expressed as $\mathrm{ug} / \mathrm{ml}$. $\mathrm{min}$.

Following $250 \mathrm{mg}$ levodopa, the plasma dopa levels rose faster in the treated group than in the controls, attaining peak values at one hour of $600 \mathrm{ng} / \mathrm{ml}$. and $350 \mathrm{ng} / \mathrm{ml}$. respectively. The plasma integrated area (PIA) for the treated patients was $89.2 \pm 32.1 \mathrm{ug} / \mathrm{ml}$. $\mathrm{min}$. and $46.3 \pm 7.7 \mathrm{ug} / \mathrm{ml}$. $\mathrm{min}$. for the controls $(p<0.001)$. The HVA PIAs for both groups were 71.8 45.2 and $30.5 \pm 3.2 \mathrm{ug} / \mathrm{ml}$. min. respectively $(p<0.005)$. The concurrent administration of $50 \mathrm{mg}$. carbidopa with $250 \mathrm{mg}$. levodopa produced significant changes. For the treated group, the dopa PIA increased $171 \%$ to $224.6 \pm 6.2 \mathrm{ug} / \mathrm{ml}$. $\mathrm{min}$., whereas that for the control group increased $371 \%$ to 182.7 28.6 (significance of $\%$ change $p<0.001$ ). The HVA PIAs for the two groups fell to $34.7 \pm 16.6$ and $8.9 \pm 1.8 \mathrm{ug} / \mathrm{ml}$. $\mathrm{min}$. respectively $(\mathrm{p}<0.001)$.

The increased PIAs for dopa and HVA following levodopa in the treated group are suggestive of enhanced G.I. absorption of the amino-acid; the decreased effect of carbidopa in this group could be indicative of a metabolic adaptive increase in systemic decarboxylase activity. Preliminary in-vitro erythrocyte incubation studies with pyridoxine is in support of this thesis. Following chronic dopa therapy, there results an enhanced cellular ability for synthesis of pyridoxal-5-phosphate, the required co-enzyme for decarboxylase.

\section{Long Term Therapy of Essential Tremor}

\section{T. J. Murray Halifax}

In 1972 the author reported to the Congress on the promising results of a preliminary therapeutic trial on Propranolol (Inderal) in 12 patients with essential tremor. We have 41 patients with this diagnosis and have followed 21 longterm.

In an initial 6-week double blind cross-over study it was found that $66 \%$ of patients showed definite improvement on Propranolol compared to $25 \%$ on placebo, and the degree of improvement in the treatment group was subjectively rated much higher than the place bo group. A similar but smaller study using Valium as a therapeutic agent showed the same results as placebo, but a significant number of patients selected valium over placebo at the end of the trial.

Twenty-one cases have been followed on Propranolol therapy for one to three years and at present the total results have been assessed as excellent -4 , good-4, fair-10, no change-1, and worse- 2 .

The results in patients under age 60 were excellent-4, good-1, fair- 1 , no change- 0 , and worse- 0 . The four patients with excellent results had their tremor less than 10 years and three of the four were under age 35 . The results in patients over age 60 were excellent -0 , good-3, fair-9, no change-1, and worse-2. Although $71 \%$ of our patients were over age 60 , no excellent results were seen in this group. This would suggest poorer results may be expected in any series with a high proportion of older patients.

We would suggest that Propranolol is warranted in all cases of essential tremor but the best results can be expected in younger patients with a shorter history of tremor. If there is no response in 3 months on 120 mgs. daily, it is unlikely that the patients will benefit from continuing therapy or increased dosage.

\section{Guillain-Barré Syndrome - A Clinical Review of Complications}

Bruce M. Stewart, John Norris, M. Vilaghy Toronto

Sixty patients with well-defined Guillain-Barré Syndrome were reviewed with particular reference to the development of respiratory paralysis, hypertension, pupillary abnormality, bowel and bladder abnormality, loss of sweating, loss of postural vasomotor tone and morbidity.

One-third of patients in this study required respiratory assistance. These patients in the main were those who developed the autonomic abnormalities. Several patients developed severe hypertension and these cases are reviewed with some attention. Mortality in this disease was previously linked to the respiratory and autonomic complications. In this series the mortality of $5 \%$ is much lower than that previously reported in the literature $(16 \%-25 \%)$. The management of these complications is therefore carefully stressed.

\section{Polyneuropathy After Accidental Hypothermia}

\section{J. M. Peyronnard, D. Boghen, A. J. Aguayo Montreal}

Peripheral nerve damage as a result of exposure to cold has been described mainly amongst soldiers and is rare in the civilian population. We report the case of a 26-year-old man who, following a car accident last winter, lay unconscious for several hours with most of his body submerged in a ditch filled with icy water. On admission to hospital he was severely hypothermic. He recovered well except for distal wasting of muscles and sensory impairment in all four limbs. EMG revealed widespread distal denervation. Motor conduction velocities were borderline and sensory action potentials absent. A sural nerve biopsy ( 4 weeks after injury) studied by phase and electron microscopy showed changes in myelinated (MF) and unmyelinated fibers (UNF). Amongst MF: Axonal degeneration was widespread with no evidence of primary demyelination. In UNF: measurements of internuclear distances between Schwann cells (Peyronnard, J. M., 1973) and quantitative ultrastructural studies (Aguayo, A. J. , 1973) failed to show any suggestion of fiber regeneration.

Findings in this patient indicate that intense cold exposure causes damage to myelinated and unmyelinated peripheral nerve axons. Findings in man are similar to those we have observed in the experimental animal.

Peyronnard, J. M., Aguayo, A. J. and Bray, G. M. (1973). Internuclear distances of Schwann cells in normal and regenerating unmyelinated nerve fibers. Archives of Neurology (Chicago) 29, 56-59. 
Aguayo, A. J., Peyronnard, J. M., Martin, J. B. and Bray, G. M. (1973). Responses of unmyelinated nerves to axonal transsection and neuronal loss. In: New Developments in Electromyography and Clinical Neurophysiology, ed. J. E. Desmedt, 2, 166-173. Basel, Karger.

\section{Saturday, June 22, 1974 - Morning Session}

Scientific Session II - General Papers

Chairmen: Dr. J. G. Stratford, Dr. C. H. Tator

\section{Neurophysiological Changes in Spinal Shock and Established Spasticity \\ Peter Ashby Toronto}

Neurophysiological measurements have been made on nine patients with complete spinal lesions, three during the stage of spinal shock and seven after the development of spasticity. Similar observations have been made on six normal subjects. The excitability of the Ia monosynaptic pathway (achilles tendon reflex) and the excitability of the Ia polysynaptic pathway (tonic vibration reflex) are expressed as proportions of the total motoneurone pool. The suppression of the H-reflex by vibration is used as a measure of presynaptic inhibition.

In complete spinal lesions with spinal shock presynaptic inhibition is increased. The excitability of the Ia monosynaptic and the Ia polysynaptic pathways is reduced.

In complete spinal lesions with established spasticity presynaptic inhibition gradually fails. The excitability of the Ia monosynaptic pathway becomes exaggerated but the excitability of the Ia polysynaptic pathway remains reduced.

It is postulated that enhanced presynaptic inhibition may contribute to the hyporeflexia of spinal shock.

\section{Radiofrequency Electrophrenic Respiration in Upper Cervical Cord Injury}

R. Graham Vanderlinden, S. W. Epstein and S. F. P. Mann Toronto

\section{Pathological Effect and Therapeutic Value of Durotomy in Acute Experimental Spinal Cordtrauma in Monkeys}

C. H. Tator, A. N. Sandler Toronto

\section{Facial Asymmetry in Temporal Lobe Epilepsy}

Guy Remillard, Charles Hodge, Frederick Andermann Montreal

The unexperienced examiner often notices no physical abnormality on examination of a patient with temporal lobe epilepsy. Facial asymmetry in patients with temporal lobe epilepsy, however, is very common and this has long been recognized in the folklore of experienced epileptologists. This asymmetry is more striking and usually greater than the common facial asymmetry found in the normal population. On direct questioning one finds that it has usually been observed by the patient's family, or by the patient himself.

In an attempt to assess the presence and significance of facial asymmetry in association with temporal lobe epilepsy, a pre- liminary photographic study was carried out; asymmetry was most often found when the patient was smiling or in association with other emotional facial movement, but at times also during voluntary movement and at rest.

There is flattening of the naso-labial fold and diminished pull on the angle of the mouth on the side opposite the focus.

The asymmetry may indicate a mild supranuclear facial deficit but could also relate to amygdaliod dysfunction. Its recognition may aid in the lateralization of the temporal focus which may otherwise be quite difficult to accomplish on historical grounds alone.

\section{Computerized Midline Echoencephalography Fact or Fiction?}

\section{R. M. Ford, J. M. Epps Montreal \\ Trigeminal Neuropathy \\ R. H. Wilson, Henry Berry Toronto \\ Reversible Conduction Block in Human Neuropathies}

\section{T. E. Feasby, W. F. Brown. J. Gilbert London, Ontario}

Small changes in the nerve fiber temperature have been reported to produce a reversible conduction block in experimental neuropathies, the main feature of which was segmental demyelination. (Rasminsky, 1973). To look for reversible block in human neuropathies, the latency and size of the distal muscle compound potential (MCP) evoked by supra-maximal proximal motor nerve excitation was compared when the intermediate segment of the nerve was warmed and cooled by a water jacket about the limb.

In controls and patients with primary neuronal/axonal neuropathies, the amplitude of the CMP was unchanged, even though the maximum motor conduction velocity changed in proportion to the temperature. Furthermore, in hypertrophic neuropathy, no reversible block was found even though the impuse velocities were very low. In acute idiopathic polyneuritis, however, the maximum CMP was as much as $25 \%$ larger in amplitude when the limb was cooled below $25^{\circ} \mathrm{C}$, a reversible block in single motor axons shown and 1 sural nerve biopsy studied in vitro was found to have a similar paradoxical larger compound potential when cooled.

The basis for the reversible block was not obvious because no segmental and little paranodal demuelination was found. The latter two pathological changes were much more common in the phrenic nerve of guinea pigs with experimental diphtheritic polyneuritis in which a reversible block could also be found.

The functional consequences of demyelination in nerve fibers include impulse velocity slowing, an ihcrease in the absolute refractory period and most importantly, to the production of weakness - conduction block. The present findings suggest that in human acute primary demyelinating neuropathies, there is a significant proportion of fibers that may be functionally blocked and unblocked by a change in the temperature of the nerve. The phenomenon was not observed in some more chronic neuropathies, even though there was extensive demyelination and remyelination. 